\title{
LA INVIOLABILIDAD PARLAMENTARIA A LA LUZ DE LA LEY DE PARTIDOS POLÍTICOS
}

\author{
POR \\ ALEXANDRE H. CATALA I BAS \\ Profesor Titular de Derecho Constitucional \\ Universitat de València
}




\section{SUMARIO}

1. Consideraciones previas. 2. La ley de partidos políticos. 3. La inVIOLABILIDAD PARLAMENTARIA A LA LUZ DE LA LEY DE PARTIDOS POLITICOS. 


\title{
LA INVIOLABILIDAD PARLAMENTARIA A LA LUZ DE LA LEY DE PARTIDOS POLITIICOS
}

\author{
POR \\ ALEXANDRE H. CATALA I BAS \\ ProfesorTitular de Derecho Constitucional \\ Universitat de València
}

\section{CONSIDERACIONES PREVIAS}

La Ley de Partidos Políticos diseña un nuevo panorama político o al menos, ayuda a clarificar cuales son las reglas de juego que han de regir la actuación de los partidos políticos $y$, como no, la de sus dirigentes. El objetivo último de la Ley es impedir que los intolerantes, los que hacen bandera del terrorismo, del racismo, de la xenofobia o de cualquier otro tipo de intolerancia, los que, en definitiva, no respetan la dignidad humana y los derechos fundamentales de las personas, puedan aprovecharse de una serie de instrumentos tales como el derecho de asociación o la libertad de expresión, que hacen posible la democracia, para intentar acabar con ella.

El espíritu que mueve esta Ley no puede detenerse en las puertas del Parlamento. Esta es una buena ocasión para reabrir el debate sobre determinadas instituciones parlamentarias, especialmente sobre la extensión y límites de prerrogativas, derechos y deberes parlamentarios. En este con- 
texto se sitúa el presente trabajo que pretende esbozar una serie de ideas en torno a la inviolabilidad parlamentaria a partir de los principios que inspiran la Ley de Partidos Políticos.

El panorama político tradicionalmente se ha dibujado en nuestro país a partir de una serie de variables: izquierda / derecha, nacionalismo / no nacionalismo..., perfectamente legítimas y que admiten, incluso, graduaciones en su seno. La Ley de Partidos Políticos no está pensada para incidir en estas relaciones sino que su objeto es otra variable que, por el contrario, no admite graduaciones: demócrata / no demócrata. Aquí no puede admitirse ningún tipo de titubeo. $O$ se es demócrata o no se es. No ha lugar para zonas difusas o para gama de grises. Por ello es conveniente que los representantes politicos midan sus palabras, clarifiquen sus posturas, $y$, especialmente, no mezclen o confundan los términos del debate. En este sentido no se trata de enfrentar un llamado bloque constitucionalista o bloque democrático con otro bloque llamado nacionalista. Esto es un error que conlleva una gran dosis de confusión entre la ciudadania. Los términos de debate han de situarse en el campo de la democracia y el respeto a los derechos fundamentales. Es en este campo donde se enfrentan dos bloques antagónicos: el democrático y el no democrático, de tal manera que no valen ni excusas ni malinterpretaciones ni confusiones a la hora de optar por uno u otro bloque. Sería un claro ejemplo de abuso de derecho si se pretendiere utilizar la Ley de Partidos Políticos para desencadenar una caza de brujas en el bloque democrático.

Si se parte de estas consideraciones puede admitirse que la Ley de Partidos Políticos es una medida de defensa de la democracia o, cuanto menos, de salubridad democrática, similar a las existentes en países de nuestro entorno como Alemania o Francia. Sin embargo, a nadie escapa que un instrumento creado para defender la democracia puede terminar por destruirla si su utilización no está presidida por la prudencia, en el sentido aristotélico del término, como instancia ordenadora de los conflictos. Para ello, ha de partirse de una premisa que constituye una sólida construcción del Tribunal Europeo de Derechos Humanos: el hecho de que un proyecto politico no sea compatible con la estructura de un Estado no lo convierte por este único motivo, en incompatible con la democracia pues pertenece a la propia esencia de ésta la proposición o discusión de proyectos políticos diversos, incluso los que cuestionan el modo de organización actual de un estado, siempre y cuando no supongan un ataque a la propia democracia!.

1 Vide SsTEDH Partido socialista Turco de 25 de mayo de 1998 y Partido de la Libertad y la Democracia de 8 de diciembre de 1999. 
Es preciso traer a colación una serie de casos llevados ante el Tribunal de Estrasburgo que clarifican una de las cuestiones más polémicas ¿es posible ilegalizar un partido político porque sus estatutos, su ideología, su proyecto político o su actuación o la de sus dirigentes, sean contrarios a los valores democráticos y a los derechos fundamentales sobre los que éstos se asientan, sean, en definitiva, intolerantes en cualquiera de sus manifestaciones (defensa de la superioridad de la raza blanca, defensa del terrorismo como método político, defensa del fundamentalismo religioso, etc. $)^{2}$.

En el caso de la asociación Hogar de la civilización macedónica, los demandantes, que se declaraban de origen étnico "macedonio" y tener "conciencia nacional macedónica" intentaron sin éxito registrar dicha asociación cuyos objetivos eran: a). El desarrollo cultural, intelectual y artístico de sus miembros y de los habitantes de Florina en general, así como el desarrollo de un espíritu de cooperación, de solidaridad y de amor entre ellos, b) la descentralización cultural y la preservación de las manifestaciones y tradiciones intelectuales y artísticas así como los monumentos de esta civilización y, más en general, la promoción y desarrollo de su cultura popular , y c) la protección del desarrollo natural y cultural de la región. EITEDH, en su sentencia de 8 de julio de 1998 declaró que la negativa a inscribir la asociación por parte de las autoridades griegas no era conforme al Convenio pues la conciencia de pertenecer a una minoría y desear conservar y desarrollar dicha cultura no suponía una amenaza contra la sociedad democrática. Es más, concluye elTEDH, el Estado no sólo ha de tolerar la existencia de minorías nacionales en su territorio sino que tiene la obligación de protegerlas. El Tribunal es consciente de que una asociación puede perseguir fines distintos, inconciliables con la democracia, a los proclamados, pero la negativa a su creación impide comprobar este extremo cuando ello no cabe deducirlo, de entrada, de sus estatutos.

El Partido Comunista Unificado de Turquía fue declarado ilegal, en primer lugar, por denominarse comunista, $y$, en segundo lugar, por reco-

2 La República Federal Alemana dio una respuesta positiva a la cuestión al ilegalizar, basándose en el artículo 21.1 de la Ley Fundamental de Bonn que dispone que el ordenamiento interno de los partidos deberá responder a los principios de la democracia siendo inconstitucionales los partidos que, en virtud de sus objetivos o del comportamiento de sus afiliados, se propongan menoscabar o eliminar el orden básico demorático-liberal o poner en peligro la existencia de la República Federal Alemana, al Sozialistische Reichspartei (sentencia del Tribunal Constitucional Federal de 23 de octubre de 1952) y al Kommunistische Partei Deutschlands (sentencia de 17 de agosto de 1956). 
nocer la existencia del pueblo kurdo como pueblo diferenciado del turco. EITEDH, en la sentencia de 30 de enero de 1998, consideró que tal disolución vulneraba el Convenio pues el partido había sido disuelto antes de poder iniciar sus actividades y la mera utilización del término comunista no era suficiente, por sí misma, para pensar que se pretendía la denominación de una clase social sobre las otras. En cuanto a la cuestión del reconocimiento de los derechos de los kurdos, el TEDH advirtió que el propio Partido Comunista manifestaba que trabajaría para encontrar una solución pacífica, democrática y equitativa para que los pueblos kurdo y turco pudieran vivir en paz sobre la base de la igualdad de derechos y a partir de una estructuración democrática del Estado en interés de todos, lo que descartaba, claramente el recurso a la violencia como método político.

Por su parte, el Partido Socialista Turco fue disuelto por defender la instauración, respetando las reglas de juego democráticas, de un sistema federal en el que turcos y kurdos estarían representados en pie de igualdad y sobre una base voluntaria, defendiendo, incluso el derecho a la autodeterminación del pueblo kurdo. EITEDH, en su sentencia de 25 de mayo de 1998, declaró que no se ajustaba al Convenio tal medida pues es totalmente legitimo defender un proyecto político, incluso, incompatible con los principios y estructuras de un Estado ya que en la propia esencia de la democracia está permitir la proposición y la discusión de proyectos políticos diversos, aunque pongan en cuestión el modo de organización actual de un Estado, siempre y cuando, dichos proyectos no atenten contra la propia democracia.

El Partido de la libertad y la democracia corrió igual suerte que los dos anteriores. Este partido denunciaba el régimen capitalista turco así como la opresión a que se había sometido al pueblo kurdo. En palabras propias, preconizaba la creación de un orden dominado por la paz y la fraternidad, en el que "nuestros pueblos" disfruten del derecho a la autodeterminación, manteniendo una lucha contra las corrientes y organizaciones fascistas, integristas, chauvinistas y racistas que ponen obstáculos a la solidaridad, a la unión, a la fraternidad de los pueblos y se constituía en defensor de los valores culturales, profesionales, económicos y políticos de las diferentes minorias nacionales o religiosas y de cada categoría socio-profesional, previendo la creación de una asamblea democrática que represente los intereses de los pueblos turco y kurdo y de cualquier otra minoría. Hay que tener en cuenta que si bien afirmaba que es justa y legítima la lucha de los pueblos por su independencia, por otra parte, se deducía con toda claridad que dicha lucha había de llevarse a cabo por métodos pacíficos al defender una solución pacífica y democrática al problema kurdo en la estricta aplicación de los textos internacionales tales como el Acta final de Helsinki, el Convenio Europeo de Derechos Humanos y la 
Declaración Universal de los Derechos Humanos. EITEDH en su sentencia de 8 de diciembre de 1999, declaró no adecuada al Convenio la disolución del Partido pues nada en su programa podía considerarse una apelación a la violencia o al levantamiento o a otra forma de rechazo a los principios democráticos. Todo lo contrario, el programa del partido insistía en la necesidad de realizar el proyecto político desde el respeto a las reglas democráticas.

Llegamos así al caso del Partido de la Prosperidad (Refah Partisi) que fue ilegalizado por el Estado Turco en base no a sus estatutos, que en ningún momento fueron objeto de discusión, sino a las manifestaciones de sus principales dirigentes que abogaban por la restauración de un régimen teocrático, por imponer la Sharia o ley musulmana y por defender la Yihab o guerra santa, así como el recurso a métodos violentos para alcanzar la dominación total de la religión musulmana en la sociedad. EITEDH, en su sentencia de 31 de julio de 2001, tuvo en cuenta la gravedad de estas declaraciones, el hecho de que sus autores fueran dirigentes principales del partido, que no habían sido hechas de manera esporádica o aislada sino que eran una constante, y, por último, la posibilidad real de llevar a cabo dichos objetivos, visto lo cual concluyó que la ilegalización no había vulnerado el Convenio

No hay que perder de vista que, tal como señala el Tribunal de Estrasburgo ${ }^{3}$, los partidos políticos desempeñan un papel esencial en el mantenimiento del pluralismo y del buen funcionamiento de la democracia pues, en definitiva no hay democracia sin pluralismo. $Y$ en el mismo sentido se manifiesta el Tribunal Constitucional al reconocer "la importancia decisiva que esas organizaciones tienen en las modernas democracias pluralistas" 4 , como "base esencial para la actuación del pluralismo" ${ }^{5}$, importancia que se deduce de manera evidente de cla colocación sistemática de este precepto [artículo 6] expresa la importancia que se reconoce a los partidos políticos dentro del sistema constitucional" 6 .Y ello supone que un partido politico ha de tener la posibilidad de debatir públicamente cualquier cuestión de interés público dentro del respeto a las reglas democráticas y ver de encontrar soluciones que puedan satisfacer a todos los actores involucrados. No hay que olvidar que, en último extremo, el Estado es

3 Vide SsTEDH Partido Comunista Unificado de Turquía de 30 de enero de 1998, Partido Socialista Turco de 25 de mayo de 1998 y Partido de la Prosperidad de 31 de julio de 2001.

${ }^{4}$ STC 3/1981, de 2 de febrero, FJ 1.

5 STC 85/1986, de 25 de junio, FJ 2.

${ }^{6}$ STC 85/1986, de 25 de junio, FJ 2. 
el garante del pluralismo y sin pluralismo no hay democracia. Es más, el grado de reconocimiento del derecho de asociación en un Estado muestra el estado de salud de su democracia.

Indudablemente, advierte el TEDH, un partido político puede hacer campaña en pro de un cambio de la legislación o de las estructuras legales o constitucionales de un Estado, siempre y cuando, eso sí, respete dos condiciones: primera, que los medios utilizados a este fin sean a todas luces legales y democráticos; segunda, que el cambio propuesto sea, asimismo, compatible con los valores democráticos fundamentales. Por otra parte, sigue señalando el Tribunal de Estrasburgo, los objetivos de un partido político no se derivan exclusivamente de lo que se señala en sus estatutos sino también de su actuación, especialmente de sus dirigentes. Ahora bien, el papel esencial que desempeñan los partidos políticos en una democracia obliga a examinar con el máximo rigor estas cuestiones, observar, por tanto la gravedad de las declaraciones, sus autores, si se trata de declaraciones aisladas o esporádicas, o, en cambio, se trata de una toma de postura firme y sólo concluir la ilegalización de un partido cuando quede constatado, sin ningún género de dudas, que se mueve fuera de la legalidad. Como advierte RUBIO LLORENTE, "no hay democracia sin libre competencia entre partidos $y$ en consecuencia la decisión de excluir del juego a uno de ellos roza los límites mismos de la democracia y obliga a extremar el cuidado para no traspasarlos»?.

En definitiva, es legítima la disolución de un partido que no respete los valores democráticos y, por tanto, los derechos fundamentales de los ciudadanos, siempre y cuando dicho atentado sea grave y quede probada su realidad de forma fehaciente a partir de su programa o estatutos a partir de sus campañas electorales, de las manifestaciones de sus dirigentes, de la posibilidad real de llevar a cabo dichos objetivos incompatibles con el sistema democrático, etc. Nos movemos en un campo sinuoso en que hay que ser muy escrupuloso a la hora de decidir la ilegalización de un partido político tal como lo ha sido elTEDH que sólo en un caso ha defendido la legalidad de la disolución. Cada caso reviste una gran complejidad pero hay que diferenciar claramente lo que es un ataque, grave, a la democracia (que supone, en definitiva intentar destruirla con todo lo que ella conlleva) de lo que no pasa de ser una discusión sobre la organización o estructura de un Estado, perfectamente legítima si se lleva a cabo por medios democráticos.

7 Rubio LloRENTE, Francisco, "Los limites de la democracia», El País, 26 de abril de 2002. 


\section{LA LEY DE PARTIDOS POLÍTICOS}

La reciente Ley de Partidos políticos nos merece una serie de consideraciones que pasamos a esbozar.

En primer lugar, da la impresión de ser una ley como dice el profesor Marc CARRILLo ad casum ${ }^{8}$, encaminada a ilegalizar aquellas formaciones políticas que defiendan el terrorismo. Ello puede deducirse del propio informe del Consejo General del Poder Judicial en el que se llega a afirmar que:

«El terrorismo es la realidad sobre la que se articula la estructura del párrafo 3 del artículo 8 (como lo evidencia el dato de que en doce ocasiones se menciona), de lo que cabe inferir que, desaparecido el terrorismo de la realidad social por la que, lamentablemente, atraviesa la sociedad española, el artículo 8 del Anteproyecto de Ley Orgánica ${ }^{9}$ que se informa carecería de sentido y alcance".

Efectivamente, hay otras muchas conductas intolerantes, como el racismo y la xenofobia, el integrismo o el fundamentalismo, a las que se hace referencia en la Exposición de motivos de la Ley y en el punto 2 a del artículo $9^{10}$, que luego no se concretan en el articulado. De hecho el artículo 9.3. que describe las actividades que pueden dar pie a la ilegalización de un partido político se centra en el terrorismo. Se tendría que haber aprovechado la oportunidad, vista la experiencia europea actual con partidos de indudable corte racista, para regular con mayor detenimiento la posible ilegalización de un partido que practicara otro tipo de intolerancia distinta a la defensa o justificación del terrorismo.

La segunda consideración, versa sobre la cuestión de que la Ley persigue actuaciones no ideas. Señala el profesor Manuel ARAGON que «nuestra Constitución, a diferencia de la de Alemania, permite su revisión total y

8 CArrillo, Marc, "Desafortunada y Traumática», El Pais, 21 de abril de 2002. Martinez Sospedra, Manuel, "Ley de Partidos", El Pais, 18 de abril de 2002, la califica de ley ad hoc.

9 Artículo 9

10 «2.Un partido político será declarado ilegal cuando su actividad vulnere los principios democráticos, particularmente cuando con la misma persiga deteriorar o destruir el régimen de libertades o imposibilitar o eliminar el sistema democrático, mediante alguna de las siguientes conductas, realizadas de forma reiterada y grave: a)Vulnerar sistemáticamente las libertades $y$ derechos fundamentales, promoviendo, justificando o exculpando los atentados contra la vida o la integridad de las personas, o la exclusión o persecución de personas por razón de su ideología, religión o creencias, nacionalidad, raza, sexo u orientación sexual. 
por ello la democracia española no es, como la alemana, una "democracia militante " ${ }^{11}$. Aunque ello fuera asi, cabe advertir que nuestra Constitución no es ideológicamente neutral sino que apuesta decididamente por la democracia. Así se desprende de artículos como el 1 o el 27. Al respecto cabe distinguir entre orden constitucional y sistema democrático. ¿Es posible mantener que cualquier proyecto $u$ objetivo es compatible con la Constitución, siempre y cuando no se defienda mediante una actividad que vulnere los valores democráticos o los derechos fundamentales de los ciudadanos?. La respuesta afirmativa nos puede llevar a aceptar la creación de partido nazi que sería legal mientras no montara una noche de los cristales rotos, o un partido racista mientras no se dedicaran sus afiliados a apalear a vagabundos o a inmigrantes. Como ya ha señalado el profesor RUBIO LLORENTE, haciéndose eco de la jurisprudencia del TEDH, la democracia no es incompatible en modo alguno con una regulación de los partidos políticos que prevea su ilegalización cuando fines y medios son incompatibles con la democracia. "No ciertamente porque quieran cambiar la Constitución o las leyes, sino porque pretenden conseguirlo con medios que no son plenamente legales y democráticos, o porque el fin que se proponen no es compatible con los principios básicos de la democracian ${ }^{12}$. Los fines presuponen un proyecto, una ideología, un programa para los cuales se ponen unos medios. Claramente lo advierte el profesor MARTINEZ SOSPEDRA en los siguientes términos: "quienes ingenuamente alegan que sólo se puede ilegalizar por actos y no por ideas harian bien en repasar la jurisprudencia del Tribunal Europeo de Derechos humanos... Y es que la legitimación de la violencia o el sostenimiento de políticas incompatibles con los principios mismos de la democracia no es que requiera de ideas, es que sólo puede hacerse mediante ideas" "13. Y en el mismo sentido se manifiesta Fernando SAVATER con relación al lema "Todas las ideas, todos los proyectos, todas las personas» que presidió la manifestación del 15 de

11 Aragon Manuel, "Sin serios reparos jurídicos», El País, 21 de abril de 2002. Considera este autor que es correcto que la ley prevea la disolución de los partidos que ensalzen el terrorismo o colaboren con él'n.

12 Rubio Llorente, Francisco, "Los límites de la democracia», El País, 26 de abril de 2002. Al respecto recordar en el artículo 21.2 de la Ley Fundamental de Bonn a cuyo tenor puede declararse inconstitucional un partido que "por sus fines o por el comportamiento de sus miembros tiendan a desvirtuar o eliminar el ordenamiento constitucional democrático liberal o a poner en peligro la existencia de la República Federal alemanan. Un análisis reciente de la prohibición de partidos en Alemania puede verse en IÑIGUEZ, Diego y FRIEDEL, Sabine, "La prohibición de partidos políticos en Alemania", Claves, n. ${ }^{\circ} 122,2002$, pp. 30 y ss.

13 Martinez Sospedra, Manuel, "Ley de Partidos»..., op. cit. 
julio contra esta Ley. Se pregunta el filósofo ¿todas las ideas?.Y al respecto responde: uninguna ley de este mundo ni del otro puede prohibir tener una idea ni tener una mala idea: lo más que puede aspirarse es a obstaculizar en la medida de lo posible la difusión y propaganda de algunas consideradas especialmente dañinas. $Y$ los regímenes democráticos se dedican a ello desde mucho antes de que nadie pensara en esta ley. Cuando un profesor, por ejemplo, utiliza un libro de texto en el que sostiene la inferioridad de unas razas respecto a otras, la ineptitud de la mujer para ciertas funciones públicas, el carácter patológico de la homosexualidad o justifica los campos de exterminio nazis, se prohibe su docencia sin demasiadas contemplaciones. Si muchas ideas son inaceptables como materia escolar democrática, no parece razonable aceptar acríticamente cualquier planteamiento ideológico en los partidos políticos destinados a ponerlas en práctica» ${ }^{14}$. La propia ley entra en el terreno de los fines en su artículo 9.3.a. y los fines presuponen ideas, y en su artículo 9.3.b se refiere a fomentar una cultura de confrontación ${ }^{15}$. Entramos, pues, en el terreno de las ideas $o$, si se quiere, de los proyectos, pues este tipo de actuaciones requieren de un proyecto previo. La defensa del terrorismo o de la violencia callejera supone un proyecto, un objetivo: atemorizar y conseguir por medio del miedo y la coacción un fin.

No hay que perder de vista, por otra parte, que la difusión de la intolerancia es causa de violaciones de derechos fundamentales. Unas veces de forma indirecta, en cuanto pueden incitar a la violencia a determinadas personas o grupos que, con posterioridad pueden atentar contra la vida o la integridad de las víctimas (asi lo afirmó, la ComEDH en su Decisión sobre el caso Purcell y otros c. Irlanda de 16 de abril de 1991) otras de forma directa, en la medida en que dichos mensajes por si mismos son causantes de violaciones de derechos como la propia integridad moral o el derecho al honor al causar

14 Savater, Fernando, "Ideas, Proyectos y personas", El Pais, 8 de junio de 2002.

15 Se entenderá que en un partido político concurren las circunstancias del apartado anterior cuando se produzca la repetición o acumulación de alguna de las conductas siguientes: a) Dar apoyo político expreso o tácito al terrorismo, legitimando las acciones terroristas para la consecución de fines políticos al margen de los cauces pacíficos y democráticos o exculpando y minimizando su significado y la violación de derechos fundamentales que comporta. b) Acompañar la acción de la violencia con programas $y$ actuaciones que fomentan una cultura de enfrentamiento y confrontación civil ligada a la actividad de los terroristas, o que persiguen intimidar, hacer desistir, neutralizar o aislar socialmente a quienes se oponen a la misma, haciéndoles vivir cotidianamente en un ambiente de coacción, miedo, exclusión o privación básica de las libertades, y, en particular, de la libertad para opinar y para participar libre y democráticamente en los asuntos públicos. 
sensaciones de temor, humillación o vejación. Esta segunda situación puede producirse no sólo cuando el mensaje se dirige a la víctima de forma personal sino también cuando las declaraciones intolerantes se dirigen de forma innominada o genérica al colectivo del que forma parte la víctima.

Estos sentimientos de sufrimiento y humillación pueden llegar al extremo de suponer un ataque al derecho a la integridad moral de los ciudadanos atacados por los intolerantes. Las amenazas, los insultos, las burlas pueden producir un estado grave de desasosiego constitutivo de tortura o de un trato inhumano o degradante. La prohibición de este tipo de actuaciones, tal como dice COHEN-JONATHAN, «tiene un contenido absoluto en la medida que no conlleva ninguna excepción y no es susceptible de ninguna derogación "16. Advierte SUDRE en el mismo sentido que la prohibición de la tortura y los tratos inhumanos y degradantes constituye el "núcleo duro" de los derechos fundamentales" ${ }^{17}$. Nuestra Constitución es clara al respecto al expresar en su artículo 15, como pone de relieve BAROUIN SANZ, "que el derecho a estar libre de torturas y de penas inhumanas o degradantes no puede vulnerarse en ningún caso, lo que debe ser interpretado literalmente, (...) en el sentido de que no cabe excepción alguna a la antijuridicidad de estos hechos" ${ }^{18}$.

En la STEDH Irlanda C. Reino Unido, por ejemplo, señala el Tribunal de Estrasburgo que son tratos degradantes los que «podian crear en las víctimas sentimientos de temor, angustia, y de inferioridad, susceptibles de humillarles, envilecerles y de quebrantar, en su caso, su resistencia física y moral ${ }^{19}$. Todos estos sentimientos, como reconoce el propio Tribunal en la STEDH Lehideux e Isorni de 23 de septiembre de 1998 están presentes en las víctimas de la difusión de los mensajes de los intolerantes. Y esto obliga a los poderes públicos a poner fin de forma inmediata a tales vulneraciones si no quieren incurrir en ningún tipo de responsabilidad pues si bien el CEDH habla de "violaciones de las Altas Partes Contratantes», elTEDH ha considerado por vía jurisprudencial que no sólo se da esa eficacia vertical, sino que las disposiciones del Convenio pueden ser aplicables incluso en

16 Cohen-Jonathan, Gérard. La Convention Européenne des Droits de l'Homme. Económica, París, 1989,286.

17 SuDRE, Frédéric. "La notion de «peines et traitements inhumains ou dégradants" dans la jurisprudence de la Commission et la Cour Européennes des droits de l' homme. Revue Générale de Droit International Public, 1984, p. 829.

18 Barouin SANZ, Jesús, Los delitos de tortura y tratos inhumanos y degradantes, Edersa, 1992. pp. 264.

${ }^{19}$ Esta doctrina ha sido asumida por el Tribunal Constitucional. Al respecto vide STC 65/1986 de 22 de marzo. 
las relaciones particulares, eficacia horizontal (la llamada Drittwirkung) ${ }^{20}$. Por lo tanto, los poderes públicos, como garantes de los derechos fundamentales, no pueden quedarse impasibles ante este tipo de actuaciones sino que tienen la obligación, con escrupuloso respeto al principio de legalidad y guiados por el principio de proporcionalidad, de poner fin a tales perturbaciones, lo que exige una pluralidad de medidas, entre las que deben ocupar un puesto principal las campañas de concienciación y educación en el respeto de los derechos humanos, dirigidas principalmente a los jóvenes. El futuro de la democracia depende, en buena medida, de la educación de los jóvenes en el respeto a los derechos humanos. Como advertía el profesor TOMAS Y VALIENTE, "la educación humanista debe consistir en la enseñanza de la libertad ${ }^{21}$.

En definitiva, la jurisprudencia del TEDH habla no solo de medios sino también de fines, de objetivos, de proyectos contrarios a la democracia. Para este Tribunal no cualquier ideologia o proyecto es compatible con la democracia. Los órganos de Estrasburgo han tenido ocasión de advertirlo especialmente con relación al nacionalsocialismo y/o la negación del Holocausto. Así en la STEDH Lehideux e Isorni de 23 de septiembre de 1998 tajantemente se señaló que "la justificación de una política pronazi no puede beneficiarse de la protección del artículo $10 \mathrm{CEDH}$ ”. De forma similar en la STEDH Ibrahim Aksoy, de 10 de octubre de 2000 se advirtió que "no hay duda de que las declaraciones tendentes a propagar la idea de una raza superior no pueden beneficiarse del artículo 10 $\mathrm{CEDH}{ }^{22}$. Ello no obstante, cabe advertir que la jurisprudencia de nuestro Tribunal Constitucional no ha sido tan firme sobre esta cuestión. Así en las

20 Ejemplo de esta eficacia horizontal es la Stedh Özgür Gündem c. Turquía de 16 de marzo de 2000, en la que elTEDH falló que el Estado demandado había vulnerado el artículo $10 \mathrm{CEDH}$, que consagra la libertad de expresión, como consecuencia de su actitud pasiva ante los ataques violentos de que eran objeto dicho medio de comunicación y las personas que en él trabajaban.

21 Tomas y VAlIente, Francisco, "El uso de la libertad», A orillas del Estado, Taurus, 1996, p. 107.

22 Al respecto señalar la importante labor llevada a cabo por la ComEDH inadmitiendo las demandas de quienes habian sido sancionados por las autoridades por propagar este tipo de ideología. Entre otras, Decisiones de inadmisibilidad casos Glimmerveen y Hagenbeek c. Holanda de 11 de octubre de 1979, X c. Alemania de 16 de julio de 1982, T. C. Bélgica de 14 de julio de 1983, X c. Italia de 21 de mayo de 1976, H, W, P y K c. Austria de 12 de octubre de 1989, Otto E. F.A. Remer c. Alemania de 6 de septiembre de 1995, Honsik c. Austria de 18 de octubre de 1995, Nationaldemokratische Partei Deutschlands, Bezirksverband München-Oberbayern c. Alemania de 29 de noviembre de 1995 y Pierre Marais c. Francia de 24 de junio de 1996. 
SsTC 20/1990, de 1 de julio y 176/1995, de 11 de diciembre reconoció que es merecedora de amparo la difusión de aquellas ideologías que nieguen el sistema democrático $y$, en concreto, en la STC 214/1991, de 11 de noviembre llegará a afirmar que la negación del Holocausto está amparada por la libertad de expresión,. Ahora bien, si que dejará claro el Alto Tribunal español que no son merecedores de amparo los mensajes que de forma expresa sean racistas o defiendan o justifiquen la violencia (STC 20/1990, de 15 de octubre, 214/1991, de 11 de noviembre, 176/1995, de 11 de diciembre y 136/1999, de 20 de julio) por lo que, un tanto paradójicamente, para el Tribunal Constitucional merecería el amparo la difusión del nazismo siempre y cuando no se hiciera mención expresa a estas dos cuestiones, lo que no deja de ser un contrasentido desde el momento en que la ideología nazi es per se racista y violenta. Esta jurisprudencia entra en contradicción con el artículo 607.2 del Código Penal que castiga la apología del genocidio o con el artículo 510 del mismo cuerpo legal que castiga a los que provoquen a la discriminación, al odio o a la violencia.

En esta cuestión no hay que hacer demagogia y distinguir entre las ideologías o proyectos que pretendan variar el orden constitucional sin atentar a la democracia, perfectamente legítimos, de aquellos que lo que buscan es acabar directamente con el propio sistema democrático. La Ley de Partidos Políticos sólo habla de actuaciones y defiende que en democracia tiene cabida cualquier idea siempre que se defienda por métodos democráticos, lo que, a la luz de la jurisprudencia de Estrasburgo, es más que discutible. Disentimos del parecer del Consejo de Estado manifestada en su Dictamen de 18 de abril de 2002, basado en la jurisprudencia de nuestro Tribunal Constitucional (STC 25/1983) cuando afirma que la cuestión se reduce al «compromiso de respetar las reglas del juego político y del orden jurídico existente en tanto existe y el no intentar su transformación por medios ilegales" sin entrañar "una prohibición de representar y perseguir ideales políticos diversos de los encarnados en la Constitución y en el Estatuto (de Autonomia) siempre que se respeten las reglas del juego". Se crea una verdadera confusión entre lo que es el marco constitucional y estatutario y lo que es el sistema democrático. Una persona puede no aceptar en su totalidad dicho marco pero no por ello deja de ser demócrata como, por otra parte, se afirma en el Preámbulo de la Ley. No se trata sólo de respetar unas reglas de juego. La Constitución y los Estatutos encarnan un ideal político que no es otro que el que se desprende del artículo 1 de la Constitución: el ideal de la democracia que es preciso defender. Así se recuerda, en el Preámbulo del CEDH al unir la garantía de las libertades fundamentales a la justicia y a la paz siendo ello solamente posible partiendo de un régimen verdaderamente democrático y también en el Preámbulo de la Carta de los Derechos Fundamentales de 
la Unión Europea en los siguientes términos: "la Unión está fundada sobre los principios indivisibles y universales de dignidad de hombres y mujeres, libertad, igualdad y solidaridad; reposa en el principio de democracia y el Estado de Derecho". Ambos documentos recogen en su articulado una cláusula de defensa que impide que sus disposiciones puedan ser interpretadas en el sentido de permitir una actividad o la realización de un acto tendente a la destrucción de los derechos o libertades reconocidos en el propio instrumento internacional ${ }^{23}$. ¿Es necesario recordar aqui que Hitler subió al poder tras ganar unas elecciones?. ¿Tendremos que esperar a que se cree un partido ultra que defienda la superioridad de la raza blanca y la expulsión o la supresión de derechos de las minorías, o incluso su exterminio con una limpieza étnica como la acaecida en Kosovo, $\gamma$. que gane adeptos y se cuele en las instituciones para acometer una reforma de la Ley para que pase a considerar que determinadas ideologías o proyectos no tienen cabida en una democracia?. Los demócratas no han de tener miedo a una ley que contenga esta prohibición encaminada a que los no demócratas puedan atentar contra la democracia. Esto no supone ninguna limitación intolerable ni de la libertad ideológica, ni de la libertad de expresión ni del derecho de asociación, tal como ha puesto de relieve el TEDH. Como dice el profesor MARTINEz SOSPEDRA, no todas las ideas son respetables, ¿o acaso lo son las que mantiene Le Pen con relación, por ejemplo, a los inmigrantes?. ¿Por qué no preguntamos al respecto a los inmigrantes que se sienten amenazados por grupos y movimientos, ya con una mínima organización, que montan manifestaciones en las que se gritan consignas claramente racistas?

Da la impresión de que nos hemos quedado a mitad del camino y que habrá que esperar a que surja un partido extremista, situado fuera del espectro democrático, que empiece a ganar adeptos y a colarse en las instituciones para plantearnos esta cuestión que, por otra parte, los países de nuestro entorno la tienen resuelta en su legislación. Otra cosa es que sean más o menos firmes en su aplicación y la tibieza en este punto, la falta de firmeza, supone, desgraciadamente, dar alas a los intolerantes.

La democracia, la tolerancia y la libertad, como señaló el Canciller alemán Schröeder en un discurso en agosto de 2000, "son valores que deben ser conquistados y defendidos diariamente, en el barrio, en la fábri$c a$, en el autobús o en el tren. No es una contradicción luchar por la justi-

${ }^{23}$ Artículo $17 \mathrm{CEDH}$ y artículo 54 de la Carta. Al respecto puede verse CATALA I BAS, La (In)tolerancia en el Estado de Derecho, Ediciones Revista General de Derecho / Diputación de Castellón, 2002, Epígrafe VI: "La intolerancia y el abuso de derecho. El articulo $17 \mathrm{CEDH}$. Los lobos con piel de corderon, p. 83 y ss. 
cia y contra la intolerancia y, al mismo tiempo, proscribir a aquellos que se marginan así mismos por su odio e intolerancia».

\section{LA INVIOLABILIDAD PARLAMENTARIA A LA LUZ DE LA LEY DE PARTIDOS POLÍTICOS}

Se hace muy difícil pensar que el espíritu que ha guiado la elaboración de la Ley de Partidos, que no es otro, como hemos señalado, que el de impedir que los intolerantes acaben con la democracia, que los intolerantes vulneren sistemáticamente los derechos fundamentales de las personas, quede frenado a las puertas del Parlamento. No hay que olvidar que el Parlamento, como cualquier otro poder del Estado está sujeto al principio de legalidad, por lo que sus actuaciones o la de sus miembros son susceptibles de generar responsabilidad, civil o penal, según los casos; lo contrario seria crear una impunidad parlamentaria no encajable en el Estado de Derecho donde los poderes públicos responden de sus actuaciones y vulneradora del derecho a la tutela judicial efectiva. Cualquier actuación de cualquier poder público no respetuosa con la legalidad vigente ha de poder ser llevada ante los tribunales sin que ello pueda ser considerada, con relación al Parlamento, un menoscabo del principio de separación de poderes ni una injerencia en su independencia.

El Parlamento sigue siendo el eje vertebrador de la vida política de una democracia. Es en sede parlamentaria donde entran en contacto los partidos políticos más importantes, los que han obtenido representación y donde, en gran medida, mayoría y minoría hacen realidad la concordia discors propia de la democracia de tal suerte que lo que emana del Parlamento no es únicamente la voluntad del grupo parlamentario mayoritario sino el resultado de un tira y afloja, de un consenso a base de mutuas renuncias entre las principales fuerzas políticas parlamentarias. EI parlamentarismo significa, en palabras de KELSEN, "formación de la voluntad decisiva mediante un órgano colegiado elegido por el pueblo en virtud de sufragio general e igual, o sea democrático, obrando a base del principio de la mayorían ${ }^{24}$. Señalaba ScHMITT, que la ratio del Parlamento radica en un proceso de controversias entre contradicciones y opiniones, de lo que resultaría la auténtica voluntad estatal. Así pues, lo esencial del Parlamento es "la deliberación pública de argumento y contraargumento, el debate público y la discusión pública» ${ }^{25}$, "el Parlamento no debe ser

24 KelSEN, Hans., Esencia y valor de la democracia, Labor, 1934, p. 50.

${ }^{25}$ ScHMIT, Carl., Sobre el parlamentarismo, Tecnos, 1990, p. 43 
sólo un miembro del equilibrio, sino precisamente por ser el poder legislativo, tiene que estar equilibrado en sí mismo. Todo esto se basa en un modo de pensar que crea la multiplicidad por doquier, a fin de instaurar, en un sistema de negociaciones, en lugar de una unidad absoluta, el equilibrio resultante de una dinámica inmanente ${ }^{26}$. En definitiva el Parlamento como órgano deliberante y el parlamentarismo como government by discussion.

Por lo tanto, la formación de la voluntad en el órgano colegiado se ha de producir mediante el debate y la discusión pública en condiciones de equilibrio interno. Que la voluntad del Parlamento se genere sin obstáculos ni presiones externas, sin prácticas que la desvirtúen es una de las cuestiones centrales a la hora de estudiar este órgano pues su voluntad crea y deroga normas, da y quita la confianza al Ejecutivo y provee cargos tan esenciales en nuestro país como el Defensor del Pueblo o los miembros del Tribunal Constitucional. De su voluntad depende también proceder o no a reformar la Constitución, celebrar o no un tratado internacional e, incluso, declarar la guerra a una potencia enemiga. De ahí que surjan una serie de instituciones cuyo objetivo es velar para que esta voluntad se genere libremente. De esta manera, por ejemplo, el artículo $66.2 \mathrm{CE}$ otorga a las Cortes autonomía presupuestaria y el artículo 72 CE autonomía reglamentaria; el artículo 66.3 CE, por su parte, advierte que las Cortes son inviolables y el artículo 67.2 CE pone de manifiesto que Diputados y Senadores no están ligados por mandato imperativo Como señala el profesor Pedro DE VEGA, "la mecánica de la discusión y el descubrimiento de la verdad contrastando opiniones ajenas, exige la libertad de quien discute. De ahi la justificación del mandato representativo en el parlamentarismo moderno. Si la esencia de la política parlamentaria es la deliberación, y habida cuenta que la deliberación no es posible bajo la forma del mandato imperativo, el mandato representativo constituye una exigencia ineludible del sistemas ${ }^{27}$. De entre las instituciones que persiguen dicho objetivo, merecen ser destacadas las prerrogativas parlamentarias. Como señala el Tribunal Constitucional en su sentencia 22/1997, de 11 de febrero, las prerrogativas aparecen unidas al derecho a ocupar cargos públicos reconocido en el artículo 23.2 de la Constitución española. Este precepto garantiza, no sólo el acceso igualitario a las funciones y cargos públicos, sino también que los que hayan accedido a los mismos se mantengan en ellos sin perturbaciones ilegítimas y los desempeñen de conformidad con lo que la ley dispon-

${ }^{26}$ SCHMITT, Carl., Sobre el parlamentarismo..., op. cit. p. 52.

27 De Vega Garcia, Pedro., "La función legitimadora del Parlamento", en PAU VALL, F., Parlamento y opinión pública, Tecnos, 1995, p. 233. 
ga ya que en otro caso la norma constitucional perderia toda eficacia si, respetado el acceso a la función o cargo público en condiciones de igualdad, su ejercicio pudiera resultar mediatizado o impedido sin remedio jurídico. Para garantizar lo anterior es por lo que se rodea la función parlamentaria de una serie de derechos y prerrogativas. La cuestión central es averiguar la necesidad de mantener algunas de estas prerrogativas en los estados democráticos actuales.

Las prerrogativas implican, como advierte BISCARETTI, excepciones al derecho en relación con las funciones públicas que el parlamentario ha de desarrollar ${ }^{28} 29$. Solo será legítima su existencia si existe una verdadera causa que las justifique y además, en el caso concreto, dicha causa ha de quedar probada de manera convincente pues como límite a una serie de derechos fundamentales tales como el derecho a la tutela judicial efectiva y de acuerdo con la doctrina del TEDH con relación a los límites asumida por nuestroTribunal Constitucional, estas instituciones han de responder a una necesidad social imperiosa y demostrarse esta necesidad de forma convincente ${ }^{30}$. Asi lo ha puesto de manifiesto Fernandez Segado con relación a las prerrogativas recordando que "la concurrencia entre las "normas de libertad" y las "normas limitadoras" entraña que unas y otras operen con el mismo grado de vinculariedad $y$ actúen recíprocamente. Como resultado de esta interacción, la fuerza expansiva de todo derecho fundamental restringe el alcance de las normas que establecen límites al ejercicio de un derecho" ${ }^{31}$. Matiza esta afirmación Fernandez-Miranda y CAMPOAMOR que parte del hecho de que las prerrogativas no son privilegios al servicio de intereses privados sino que trascienden los intereses particulares de sus beneficiarios para servir a un interés superior del ordenamiento jurídico. "Por tanto, no se trata de que su interpretación deba ser restrictiva, sino estrictamente ajustada a su fundamento constitucionalı ${ }^{32}$. De ello cabe deducir que, de no existir una verdadera causa que justifique

28 Biscaretti, Paolo, Derecho Constitucional, Tecnos, 1965, p. 379. En el mismo sentido Punset, R., "Inviolabilidad e inmunidad de los parlamentarios de las Comunidades Autónomas", Revista de las Cortes Generales, núm. 3, 1984, p.123

29 Silvela, F., La Inmunidad Parlamentaria, en RGLJ, $n^{\circ}$ 76, Madrid, 1890, p. 36.

${ }^{30}$ Vide, por todas, SsTEDH Handyside, de 7 de diciembre de 1976, y Silver de 25 de marzo de 1983, y SsTC 62/1982, de 15 de octubre 171/1990, de 12 de noviembre, 136/1999, de 20 de julio.

31 Fernandez Segado, Francisco, "Las prerrogativas parlamentarias en la jurisprudencia constitucional», Revista de las Cortes Generales, núm. 38, 1996, p. 13.

32 Fernandez-Miranda y CAMPOAMOR, Alfonso, «El ámbito material de la inmunidad parlamentaria», Revista Española de Derecho Constitucional, núm. 12, 1984, p. 19. 
su existencia, no tienen cabida en el estado actual, se convierten en anacronismos $y$ en privilegios, en el sentido peyorativo de la palabra.

Advertirá SCHMITT que «todos los órganos y normas específicamente parlamentarios cobran sentido sólo por la discusión y la publicidad... [Esto] es válido para la reglamentación de la libertad de expresión y las inmunidades de los parlamentarios [que] devienen incomprensibles si no se cree en el principio de la discusión pública» ${ }^{33}$. Los representantes políticos gozan de unos amplios márgenes a la hora de hacer uso de la libertad de expresión. Si bien es cierto que han de soportar fuertes criticas en el ejercicio de su función, tal como puso de relieve elTEDH en su sentencia Lingens de 8 de julio de 1986 al afirmar que los límites de la crítica permitida son más amplios pues se exponen inevitablemente a una fiscalización atenta de sus actos y gestos tanto por los periodistas como por la multitud de ciudadanos, no lo es menos, como advierte el propio TEDH en la sentencia Castells de 23 de abril de 1992, que la libertad de expresión adquiere una importancia particular cuando es ejercida por un representante político en la medida en que es necesario que la opinión pública conozca lo que piensan sus representantes, por lo que las injerencias en este derecho han de ser objeto de un control riguroso. Ello no obstante, la amplitud en su reconocimiento no se extiende al extremo de amparar, como hemos visto anteriormente, los mensajes intolerantes. $Y$ en este sentido puede traerse a colación las SsTEDH Piermont de 27 de abril de 1995 y Abrahim Aksoy de 10 de octubre de 2000 . En la primera de ellas, la demandante, parlamentaria alemana, fue expulsada de la Polinesia francesa por participar a en una serie de manifestaciones pacifistas en contra de las pruebas nucleares en la zona Y por defender la independencia de dichos territorios de Francia. En la segunda, el demandante, político turco, fue sancionado por defender los derechos del pueblo kurdo y por abogar por una solución pacífica al conflicto que pasara por dicho reconocimiento. En ninguno de los dos casos se defendían tesis intolerantes tales como la utilización de la violencia como forma para solucionar el conflicto, por lo que ambos demandantes fueron amparados en su libertad de expresión por el TEDH. Ello no obstante, no puede se amparado el mensaje que contiene una fuerte carga de intolerancia, como, por ejemplo, la defensa de la violencia para alcanzar objetivos políticos. En este sentido nos remitimos a la STEDH Zana de 25 de noviembre de 1997 en la que no se amparó al demandante por defender los métodos violentos del PKK y a la Decisión de inadmisibilidad Rufi Osmani de 11 de octubre de 2001 en la que tampoco se amparó al demandante al haber apelado a la violencia para defender su proyecto político.

${ }^{33}$ SCHMITT, Carl, Sobre el parlamentarismo..., op. cit. pp. 5 y 6. 
Pues bien, hay un ámbito, el parlamentario, en el que la libertad de expresión del representante popular goza de la impunidad más absoluta. La prerrogativa de la inviolabilidad impide perseguir al parlamentario por las opiniones manifestadas, sean las que sean, en el ejercicio de sus funciones, lo que supone que un parlamentario, en el ejercicio de sus funciones puede defender el terrorismo como método político, la superioridad de la raza blanca como dogma, la limpieza étnica de un territorio como política, etc. sin que nadie, salvo la Cámara pueda sancionarlo de acuerdo con su reglamento por este tipo de manifestaciones.

La inviolabilidad supone la irresponsabilidad jurídica de los parlamentarios por los votos emitidos y opiniones vertidas en el ejercicio de sus funciones. Aparece recogida en el artículo 71.1 de la Constitución. Su objeto, de acuerdo con la STC 51/1985, de 10 de abril es la preservación de un ámbito cualificado de libertad en la crítica y en la decisión sin el cual el ejercicio de las funciones parlamentarias podría resultar mediatizado y frustrado, por ello el proceso de libre formación de voluntad del órgano. En nuestro ordenamiento se perfila con carácter absoluto, es decir, no podrá ser perseguida ninguna opinión de un parlamentario en el ejercicio de su cargo; o dicho de otro modo, ninguna opinión manifestada por el parlamentario en el ejercicio de sus funciones generará responsabilidad alguna por su parte. En países como Bélgica, Francia o Italia, la inviolabilidad se configura también con este carácter absoluto. En otros, es objeto de límites: la Ley Fundamental de Bonn en su artículo 46.1. excluye las expresiones calumniosas y en sentido similar se manifiesta el artículo 61.1. de la Constitución griega.

Esta prerrogativa conlleva, en definitiva, configurar la libertad de expresión del parlamentario en el ejercicio de su cargo como un derecho absoluto. La cuestión es si actualmente ello es necesario. En un sistema democrático como el nuestro cabe poner en tela de juicio la necesidad del carácter absoluto de la inviolabilidad, salvo, claro está, que se dude de la independencia e imparcialidad del Poder Judicial. En nuestro Código Penal, artículos 206 y 209, las calumnias y las injurias hechas con publicidad merecen una punibilidad mayor sobre la base de que la publicidad supone un mayor quebranto para el honor del ofendido. Qué mayor publicidad que una injuria o calumnia proferida por un parlamentario en el ejercicio de sus funciones, es decir, en un pleno o comisión, con todos los medios de comunicación presentes. Como señala Perez Serrano, «el parlamentario puede, cuando olvida las moderaciones éticas y de obligada corrección, ofender, ultrajar a personas e instituciones, denostar a autoridades y particulares, imputar delitos, utilizar falsedades, y sin embargo, el agraviado, que tendría expedito el camino de los Tribunales en otro caso, ha de resignarse pacientemente, sin que se le admita ni aun el derecho a 
rectificación justiciera y proporcionada. Todo ello con la inmensa agravante de la publicidad clamorosa que la imputación alcanza al ser difundida por el tornavoz insuperable de la tribuna parlamentaria y de los diarios» ${ }^{34}$ ¿Merecen el amparo de la inviolabilidad el mensaje de defensores del genocidio o de la violencia como método político?. En este sentido ya se: han oído en nuestros parlamentos voces a favor del terrorismo ante las. cuales no puede hacerse nada. Que se diga con posterioridad que el: Ministerio Fiscal va a actuar al respecto no deja de ser, hoy por hoy, un brindis al sol. El carácter absoluto de la inviolabilidad impide que entre en juego, por ejemplo, el artículo 607.2 del Código Penal que castiga la difusión por cualquier medio de ideas o doctrinas que nieguen o justifiquen los delitos de genocidio o pretendan la rehabilitación de regímenes o instituciones que amparen prácticas generadoras de los mismos.

Mantener la postura del carácter absoluto de la inviolabilidad es, en la práctica, una válvula de escape para este tipo de mensajes, es poner en bandeja de plata el mejor foro de los existentes, el Parlamento, para su difusión con total garantía de impunidad. La inviolabilidad parlamentaria no está pensada para este fin.

Permitir que los intolerantes se escuden en esta prerrogativa es desvirtuar y corromper una institución que no estaba pensada para injuriar, calumniar, lanzar mensajes racistas o violentos, atacar a minorías étnicas, proclamar la superioridad de la raza blanca, defender el terrorismo, etc. Si el resto. de ciudadanos han de responder de tales actos con mayor motivo lo han de hacer los parlamentarios que están obligados a acatar la Constitución ${ }^{35}$.

34 Perez Serrano, Nicolás, Tratado de derecho político, Cívitas, 1984, p.780.

35 El Tribunal Constitucional se ha pronunciado de forma positiva con relación al deber de acatar la Constitución y a la obligación de prestar juramento o promesa de acatamiento Vide la STC 101/1983, de 18 de noviembre, con relación al primero:

"La sujeción a la Constitución es una consecuencia obligada de su carácter de norma suprema, que se traduce en un deber de distinto signo para los ciudadanos y los poderes públicos; mientras los primeros tienen un deber general negativo de abstenerse de cualquier actuación que vulnere la Constitución, sin perjuicio de los supuestos en que la misma establece deberes positivos (arts. 30 y 31 , entre otros), los titulares de los poderes públicos tienen además un deber general positivo de realizar sus funciones de acuerdo con la Constitución, es decir que el acceso al cargo implica un deber positivo de acatamiento entendido como respeto a la misma, lo que no supone necesariamente una adhesión ideológica ni una conformidad a su total contenido, dado que también se respeta la Constitución en el supuesto extremo de que se pretenda su modificación por el cauce establecido en los arts. 166 y ss. CE. Entendido asi el acatamiento, (...), constituye un deber inherente al cargo público, una condición, en el sentido de requisito, con independencia de que se exteriorice o no en un acto formal" (FJ 3 ). 
En definitiva, y para concluir, en un estado de derecho como el nuestro, en el que el principio de legalidad está garantizado y la independencia e imparcialidad judicial asegurada, donde el parlamentario no sufre el acoso de ningún poder del Estado, en la que esta excepción al derecho común puede utilizarse para vulnerar derechos fundamentales o para quebrar gravemente la paz social, la inviolabilidad debería perder ese carácter absoluto, introduciéndose la posibilidad de que la Cámara levantara la prerrogativa cuando el parlamentario hubiese llevado a cabo un abuso de ella difundiendo mensajes intolerantes. Para ello es imprescindible, como parece obvio, una reforma de los reglamentos parlamentarios que permita iniciar acciones contra el parlamentario que haya realizado unas manifestaciones constitutivas de delito. La cuestión no parece tan complicada. Simplemente es establecer qué tipo de actuaciones de las tipificadas en el Código Penal como delito pueden dar lugar a levantar la inviolabilidad. De entrada las recogidas en los artículos 510, 577 o 607.2 han de estar incluidas.

Con relación a la obligación de prestar juramento, introducida por el artículo 20.1.3 del Reglamento del Congreso, 12.1 del Reglamento del Senado y artículo 108. 8 de la Ley Orgánica 5/1985, de 19 de junio, del Régimen Electoral General, vide la sentencia 119/1990, de 21 de junio. Como advierte Alvarez Conde, esta obligación no pone fin al problema pues tras cumplir dichos requisitos, nada obliga al diputado a asistir a las sesiones, con lo cual puede beneficiarse de las prerrogativas sin mayor esfuerzo. Alvarez Conde, Enrique, Curso de Derecho constitucional, Vol. II, Tecnos, edición de 2000, p. 93. La razón de ser de esta medida parece clara: si el Diputado no acata la Constitución y no desempeña sus funciones parlamentarias tampoco ha de beneficiarse de las prerrogativas y derechos inherentes a dicho cargo. 